J. Phys. Chem. A, submitted

\title{
Raman Spectral Conformational Order Indicators in Perdeuterated Alkyl Chain Systems
}

\author{
$\underline{\text { SUPPORTING INFORMATION }}$
}

Zhaohui Liao and Jeanne E. Pemberton*

Department of Chemistry

University of Arizona

1306 East University Boulevard

Tucson, AZ 85721

*Author to whom correspondence should be addressed 
Another perdeuterated system investigated in this study stearic acid- $d_{35}$, a fatty acid. Raman spectra of stearic acid- $d_{35}$ at 0 and $80{ }^{\circ} \mathrm{C}$ are shown in the $v(\mathrm{C}-\mathrm{D}), v(\mathrm{C}-\mathrm{C})$, and $\delta(\mathrm{C}-\mathrm{D})$ regions in Figure S1 with corresponding peak frequencies in Table S1. Overall, these spectra resemble those of nonadecane- $d_{40}$. Certain subtle differences can be identified, however, including the lack of a combination band at $2057 \mathrm{~cm}^{-1}$ and the visible sharpness of the stearic acid- $d_{35} v_{\mathrm{s}}\left(\mathrm{CD}_{2}\right)$ mode compared to that of nonadecane- $d_{40}$. Despite these subtle differences, the same six Raman spectral order indicators can still be quantified in the stearic acid- $d_{35}$ spectra.

Raman Spectral Order Indicators for Stearic Acid- $d_{35}$. The Raman spectral order indicators $\mathrm{I}\left[\mathrm{v}_{\mathrm{a}}\left(\mathrm{CD}_{2}\right)_{2196}\right] /\left[\left[v_{\mathrm{a}}\left(\mathrm{CD}_{2}\right)_{2172}\right]\right.$ and $\mathrm{I}\left[\mathrm{v}(\mathrm{C}-\mathrm{C})_{\mathrm{G}}\right] / \mathrm{I}\left[\mathrm{v}(\mathrm{C}-\mathrm{C})_{\mathrm{T}}\right]$ as a function of temperature for stearic acid- $d_{35}$ are shown in Figures S2a and b, respectively. The phase transition for stearic acid- $d_{35}$ is abrupt as it is for nonadecane- $d_{40}$. Therefore, the phase boundaries shown are only approximate. The crystalline region spans a temperature range from -15 to $+66{ }^{\circ} \mathrm{C}$, the transition temperature is $\sim 67{ }^{\circ} \mathrm{C}$, and the liquid region is from 68 to $132{ }^{\circ} \mathrm{C}$. I $\left[v_{\mathrm{a}}\left(\mathrm{CD}_{2}\right)_{2196}\right] / \mathrm{I}\left[\mathrm{v}_{\mathrm{a}}\left(\mathrm{CD}_{2}\right)_{2172}\right]$ clearly indicates the change in conformational order of the stearic acid- $d_{35}$ with increasing thermal energy, and $\mathrm{I}\left[v(\mathrm{C}-\mathrm{C})_{\mathrm{G}}\right] / \mathrm{I}\left[v(\mathrm{C}-\mathrm{C})_{\mathrm{T}}\right]$ indicates the relative number of trans and gauche conformers present at different temperatures. The behavior of these indicators is similar to those for nonadecane- $d_{40}$ and polyethylene- $d_{4}$. However, both $\mathrm{I}\left[v_{\mathrm{a}}\left(\mathrm{CD}_{2}\right)_{2196}\right] / \mathrm{I}\left[v_{\mathrm{a}}\left(\mathrm{CD}_{2}\right)_{2172}\right]$ and I[v(CC $\left.)_{\mathrm{G}}\right] / \mathrm{I}\left[v(\mathrm{C}-\mathrm{C})_{\mathrm{T}}\right]$ experience a sharp change at $64{ }^{\circ} \mathrm{C}$ immediately prior to the melting point, suggesting the possible formation of planar gauche conformers in the solid state as has been observed previously. A similar conclusion about the formation of gauche conformations just prior to the phase transition for stearic acid- $d_{35}$ was reached by Mendelsohn and coworkers on 
the basis of the FWHM of the $v_{\mathrm{a}}\left(\mathrm{CD}_{2}\right)$ mode. ${ }^{\mathrm{S} 1}$ The behavior of this mode is discussed more below.

The correlation between $\mathrm{I}\left[\mathrm{v}(\mathrm{C}-\mathrm{C})_{\mathrm{G}}\right] / \mathrm{I}\left[\mathrm{v}(\mathrm{C}-\mathrm{C})_{\mathrm{T}}\right]$ and $\mathrm{I}\left[\mathrm{v}_{\mathrm{a}}\left(\mathrm{CD}_{2}\right)_{2196}\right] / \mathrm{I}\left[\mathrm{v}_{\mathrm{a}}\left(\mathrm{CD}_{2}\right)_{2172}\right]$ is shown in Figure S3a. In the crystalline state, although the value of $\mathrm{I}\left[v(\mathrm{C}-\mathrm{C})_{\mathrm{G}}\right] / \mathrm{I}\left[\mathrm{v}(\mathrm{C}-\mathrm{C})_{\mathrm{T}}\right]$ increases only slightly from 0.06 to 0.09 before rapidly increasing to 0.2 , the conformational order of alkyl chain decreases as indicated by the change of $\mathrm{I}\left[\mathrm{v}_{\mathrm{a}}\left(\mathrm{CD}_{2}\right)_{2196}\right] / \mathrm{I}\left[\mathrm{v}_{\mathrm{a}}\left(\mathrm{CD}_{2}\right)_{2172}\right]$ from $\sim 1.7$ to 1.2. Further into the biphasic region, the average number of gauche conformers further increases as indicated by an increase of $\mathrm{I}\left[\mathrm{v}(\mathrm{C}-\mathrm{C})_{\mathrm{G}}\right] / \mathrm{I}\left[\mathrm{v}(\mathrm{C}-\mathrm{C})_{\mathrm{T}}\right]$ from $\sim 0.2$ to 1.2. The value of $\left[v_{\mathrm{a}}\left(\mathrm{CD}_{2}\right)_{2196}\right] / \mathrm{I}\left[\mathrm{v}_{\mathrm{a}}\left(\mathrm{CD}_{2}\right)_{2172}\right]$ in this region decreases to 1.0, consistent with increased disorder. In the liquid state, the number of gauche conformers continues to increase, while the value of $\mathrm{I}\left[\mathrm{v}_{\mathrm{a}}\left(\mathrm{CD}_{2}\right)_{2196}\right] / \mathrm{I}\left[\mathrm{v}_{\mathrm{a}}\left(\mathrm{CD}_{2}\right)_{2172}\right]$ does not change significantly. These observations are consistent with those observed for nonadecane- $d_{40}$ and polyethylene- $d_{4}$.

The spectral indicators $\mathrm{I}\left[\mathrm{v}_{\mathrm{a}}\left(\mathrm{CD}_{2}\right)_{2196}\right] / \mathrm{I}\left[\mathrm{v}_{\mathrm{a}}\left(\mathrm{CD}_{2}\right)_{2172}\right]$ and $\mathrm{I}\left[\mathrm{v}(\mathrm{C}-\mathrm{C})_{\mathrm{G}}\right] / \mathrm{I}\left[\mathrm{v}(\mathrm{C}-\mathrm{C})_{\mathrm{T}}\right]$ for stearic acid- $d_{35}$, contain the same information about conformational order as those for nonadecane- $d_{40}$ and polyethylene- $d_{4}$. Specifically, I $\left[v_{\mathrm{a}}\left(\mathrm{CD}_{2}\right)_{2196}\right] / \mathrm{I}\left[\mathrm{v}_{\mathrm{a}}\left(\mathrm{CD}_{2}\right)_{2172}\right]$ essentially measures any deviation from the all-trans state in the alkyl chains, while $I\left[v(C-C)_{G}\right] / I\left[v(C-C)_{T}\right]$ indicates the relative number of true gauche conformers.

Alkyl chain coupling in stearic acid- $d_{35}$ is indicated by the ratios $\left[v_{\mathrm{s}}\left(\mathrm{CD}_{3}\right)\right] / \mathrm{I}\left[\mathrm{v}_{\mathrm{a}}\left(\mathrm{CD}_{2}\right)_{2172}\right]$ and $\mathrm{I}\left[v_{\mathrm{s}}\left(\mathrm{CD}_{2}\right)\right] / \mathrm{I}\left[\mathrm{v}_{\mathrm{a}}\left(\mathrm{CD}_{2}\right)_{2172}\right]$. These ratios are correlated to $\mathrm{I}\left[\mathrm{v}_{\mathrm{a}}\left(\mathrm{CD}_{2}\right)_{2196}\right] / \mathrm{I}\left[\mathrm{v}_{\mathrm{a}}\left(\mathrm{CD}_{2}\right)_{2172}\right]$ in Figures S3b and c, respectively. In the crystalline state, both intensity ratios decrease with decreasing $\mathrm{I}\left[\mathrm{v}_{\mathrm{a}}\left(\mathrm{CD}_{2}\right)_{2196}\right] / \mathrm{I}\left[\mathrm{v}_{\mathrm{a}}\left(\mathrm{CD}_{2}\right)_{2172}\right]$, indicating chain decoupling along with an increase in conformational disorder. This observation is similar to those made for nonadecane- $d_{40}$ and polyethylene- $d_{4}$. However, unlike the behavior observed in the biphasic and liquid states for 
nonadecane- $d_{40}$ and polyethylene- $d_{4}$, both intensity ratios for stearic acid- $d_{35}$ levels off with decreasing value of $\mathrm{I}\left[\mathrm{v}_{\mathrm{a}}\left(\mathrm{CD}_{2}\right)_{2196}\right] /\left[\left[\mathrm{v}_{\mathrm{a}}\left(\mathrm{CD}_{2}\right)_{2172}\right]\right.$. This is most likely due to the unique structure of stearic acid- $d_{35}$, in which only one methyl group per chain is present. As a result, its sensitivity to the interchain coupling is lower than that for nonadecane- $d_{40}$ or polyethylene- $d_{4}$. Once the interchain is further apart in the biphasic region, the $v_{\mathrm{s}}\left(\mathrm{CD}_{3}\right)$ band does not respond to the change in the interchain space. Despite this difference, as expected, the relationship between $\mathrm{I}\left[\mathrm{v}_{\mathrm{s}}\left(\mathrm{CD}_{2}\right)\right] / \mathrm{I}\left[\mathrm{v}_{\mathrm{a}}\left(\mathrm{CD}_{2}\right)_{2172}\right]$ and $\mathrm{I}\left[\mathrm{v}_{\mathrm{s}}\left(\mathrm{CD}_{3}\right)\right] /\left[\left[\mathrm{v}_{\mathrm{s}}\left(\mathrm{CD}_{2}\right)_{2172}\right]\right.$ is linear $\left(\mathrm{R}^{2}=0.996\right)$ as shown in Figure S3d, further supporting the view that these two ratios reflect alkyl chain interactions in a similar manner.

The correlation of the FWHM of the $v_{\mathrm{s}}\left(\mathrm{CD}_{2}\right)$ band with $\left[v_{\mathrm{a}}\left(\mathrm{CD}_{2}\right)_{2196}\right] /\left[v_{\mathrm{a}}\left(\mathrm{CD}_{2}\right)_{2172}\right]$ is shown in Figure S4 for stearic acid- $d_{35}$. In the crystalline state, the FWHM increases slightly from 15 to $20 \mathrm{~cm}^{-1}$ and then increases sharply to $30 \mathrm{~cm}^{-1}$ just prior to the phase transition. This behavior is different from that observed in both nonadecane- $d_{40}$ and polyethylene- $d_{4}$, although the abrupt increase in FWHM from 20 to $30 \mathrm{~cm}^{-1}$ is consistent with a solid state phase change prior to melting observed here and by others. ${ }^{\mathrm{S1}}$ It should also be noted that the increase in FWHM from 20 to $30 \mathrm{~cm}^{-1}$ corresponds to a similar sharp increase in gauche conformer population as indicated by $\mathrm{I}\left[v(\mathrm{C}-\mathrm{C})_{\mathrm{G}}\right] / \mathrm{I}\left[v(\mathrm{C}-\mathrm{C})_{\mathrm{T}}\right]$ from 0.09 to 0.18 immediately prior to the phase transition (see Figure S3a). Finally, in the biphasic state, the FWHM increases again up to $45 \mathrm{~cm}^{-1}$ indicating a rapid increase in the number of gauche conformers. In the liquid state, the FWHM continues to increase up to $\sim 48 \mathrm{~cm}^{-1}$ indicating a further growth of gauche conformer population. Thus, for stearic acid- $d_{35}$, the FWHM is shown to be sensitive to formation of gauche conformers in the alkyl chains, similar to what was observed for nonadecane- $d_{40}$ and polyethylene- $d_{4}$. 
The correlation between the $v_{s}\left(C D_{2}\right)$ peak frequency and $\left[v_{a}\left(C D_{2}\right)_{2196}\right] / I\left[v_{a}\left(C D_{2}\right)_{2172}\right]$ is shown in Figure S4b. Similar to that for nonadecane- $d_{40}$, the $v_{s}\left(C_{2}\right)$ peak frequency mainly reflects alkyl chain coupling for stearic acid- $d_{35}$. This indicator is not as sensitive as the values of $\mathrm{I}\left[\nu_{\mathrm{s}}\left(\mathrm{CD}_{3}\right)\right] / \mathrm{I}\left[\mathrm{v}_{\mathrm{a}}\left(\mathrm{CD}_{2}\right)_{2172}\right]$ and $\mathrm{I}\left[\mathrm{v}_{\mathrm{s}}\left(\mathrm{CD}_{2}\right)\right] / \mathrm{I}\left[\mathrm{v}_{\mathrm{a}}\left(\mathrm{CD}_{2}\right)_{2172}\right]$ discussed above; however, as shown in Figure S4b, in the crystalline and solid amorphous states, the $v_{\mathrm{s}}\left(\mathrm{CH}_{2}\right)$ frequency remains approximately constant at $2101 \mathrm{~cm}^{-1}$, although it does increases to $\sim 2107 \mathrm{~cm}^{-1}$ in the liquid state when the interchain coupling is at a minimum.

\section{References}

S1. Mendelsohn, R.; Sunder, S.; Bernstein, H. J. Biochim. Biophys. Acta 1976, 443, 613. 
Table S1. Raman peak frequencies and assignments for stearic acid- $d_{35}$.

\begin{tabular}{|c|c|c|}
\hline \multicolumn{2}{|c|}{ Stearic Acid-d $_{35}$} & \multirow[t]{2}{*}{ Assignment } \\
\hline liquid & crystalline & \\
\hline 715 & 715 & $\mathrm{CD}_{3}$ wag \\
\hline \multicolumn{3}{|l|}{727} \\
\hline \multicolumn{3}{|l|}{760} \\
\hline 843 & 828 & $\mathrm{CD}_{2}$ wag \\
\hline \multicolumn{3}{|l|}{864} \\
\hline & 914 & $\tau\left(\mathrm{CD}_{2}\right)$ \\
\hline & 920 & \\
\hline & 958 & \\
\hline & 972 & $\delta\left(\mathrm{CD}_{2}\right)$ \\
\hline & 987 & $\delta\left(\mathrm{CD}_{2}\right)$ \\
\hline & 1055 & $\delta\left(\mathrm{CD}_{3}\right)$ \\
\hline \multicolumn{3}{|l|}{1075} \\
\hline 1122 & 1124 & $v(C-C)_{G}$ \\
\hline 1136 & 1143 & $v(\mathrm{C}-\mathrm{C})_{\mathrm{T}}$ \\
\hline \multirow[t]{3}{*}{1240} & & $v(C-C)_{G}$ \\
\hline & 1249 & $v(\mathrm{C}-\mathrm{C})_{\mathrm{T}}$ \\
\hline & & $v(\mathrm{C}-\mathrm{C})_{\mathrm{T}}+\tau\left(\mathrm{CD}_{2}\right)$ \\
\hline 2073 & 2067 & $v_{\mathrm{s}}\left(\mathrm{CD}_{3}\right)$ \\
\hline \multirow[t]{2}{*}{2106} & 2101 & $v_{\mathrm{s}}\left(\mathrm{CD}_{2}\right)$ \\
\hline & 2132 & $v_{\mathrm{s}}\left(\mathrm{CD}_{3}\right)_{\mathrm{FR}}$ \\
\hline 2175 & 2170 & $v_{a}\left(C_{2}\right)$ \\
\hline \multirow[t]{2}{*}{2196} & 2196 & $v_{a}\left(C D_{2}\right)$ \\
\hline & 2218 & $v_{a}\left(C D_{3}\right)$ \\
\hline
\end{tabular}




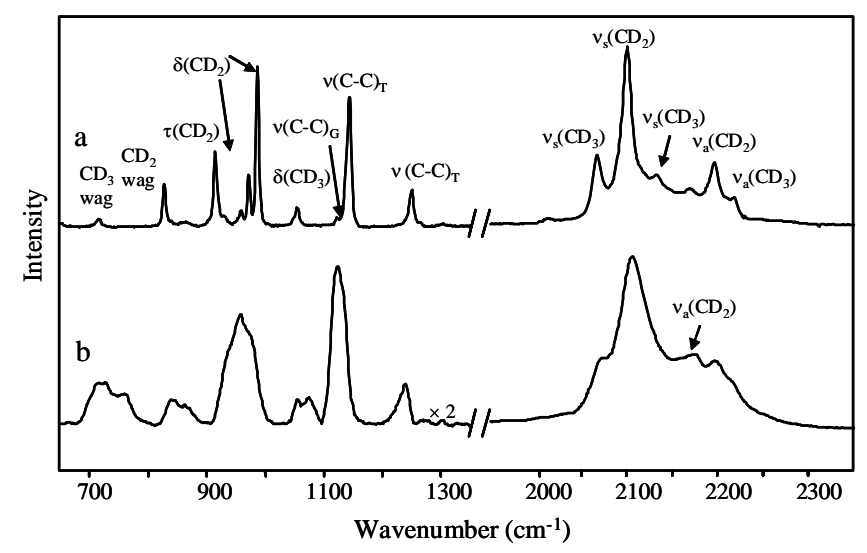

Figure S1: $\quad$ Raman spectra in the $v(C-C)$ and $\delta(C-D)$ regions for stearic acid- $d_{35}$ at a) 0 and b) $80{ }^{\circ} \mathrm{C}$. Integration times 2 and $1 \mathrm{~min}$ for low and high frequency regions, respectively.
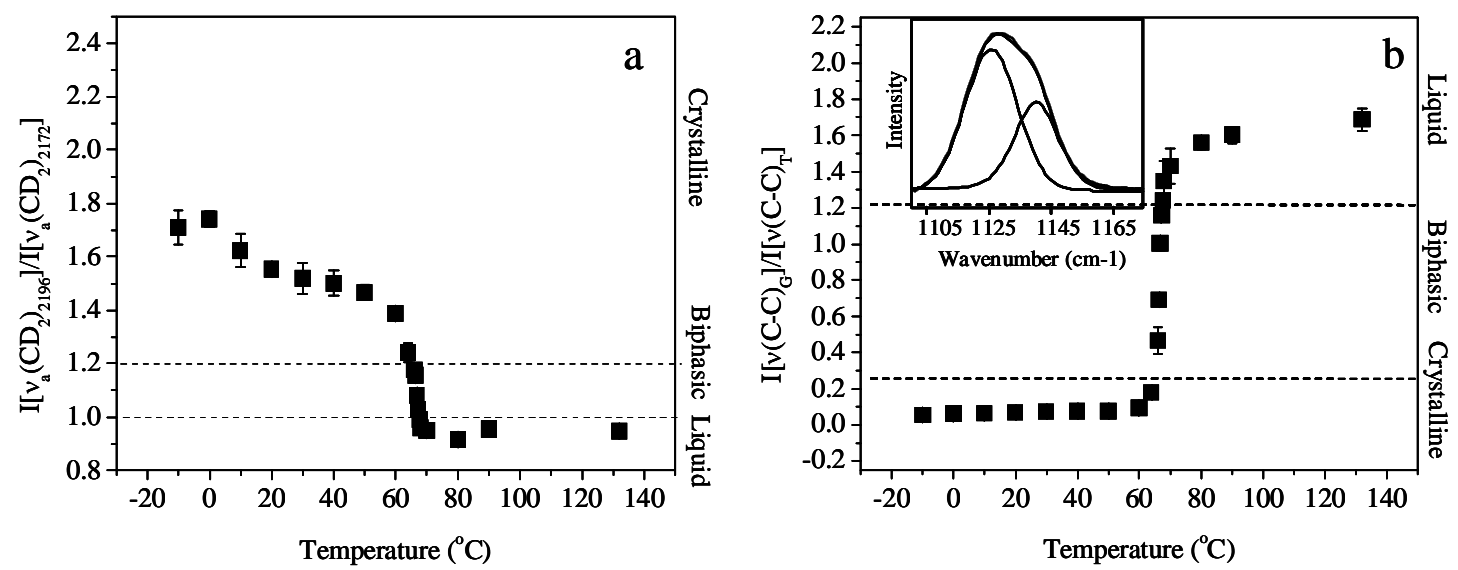

Figure S2: a) $\mathrm{I}\left[\mathrm{v}_{\mathrm{a}}\left(\mathrm{CD}_{2}\right)_{2196}\right] / \mathrm{I}\left[\mathrm{v}_{\mathrm{a}}\left(\mathrm{CD}_{2}\right)_{2172}\right]$ and b) $\mathrm{I}\left[\mathrm{v}(\mathrm{C}-\mathrm{C})_{\mathrm{G}}\right] /\left[\mathrm{v}(\mathrm{C}-\mathrm{C})_{\mathrm{T}}\right]$ as a function of temperature for stearic acid- $d_{35}$. Inset: Peak fit of $v(\mathrm{C}-\mathrm{C})$ mode at $80{ }^{\circ} \mathrm{C}$ 

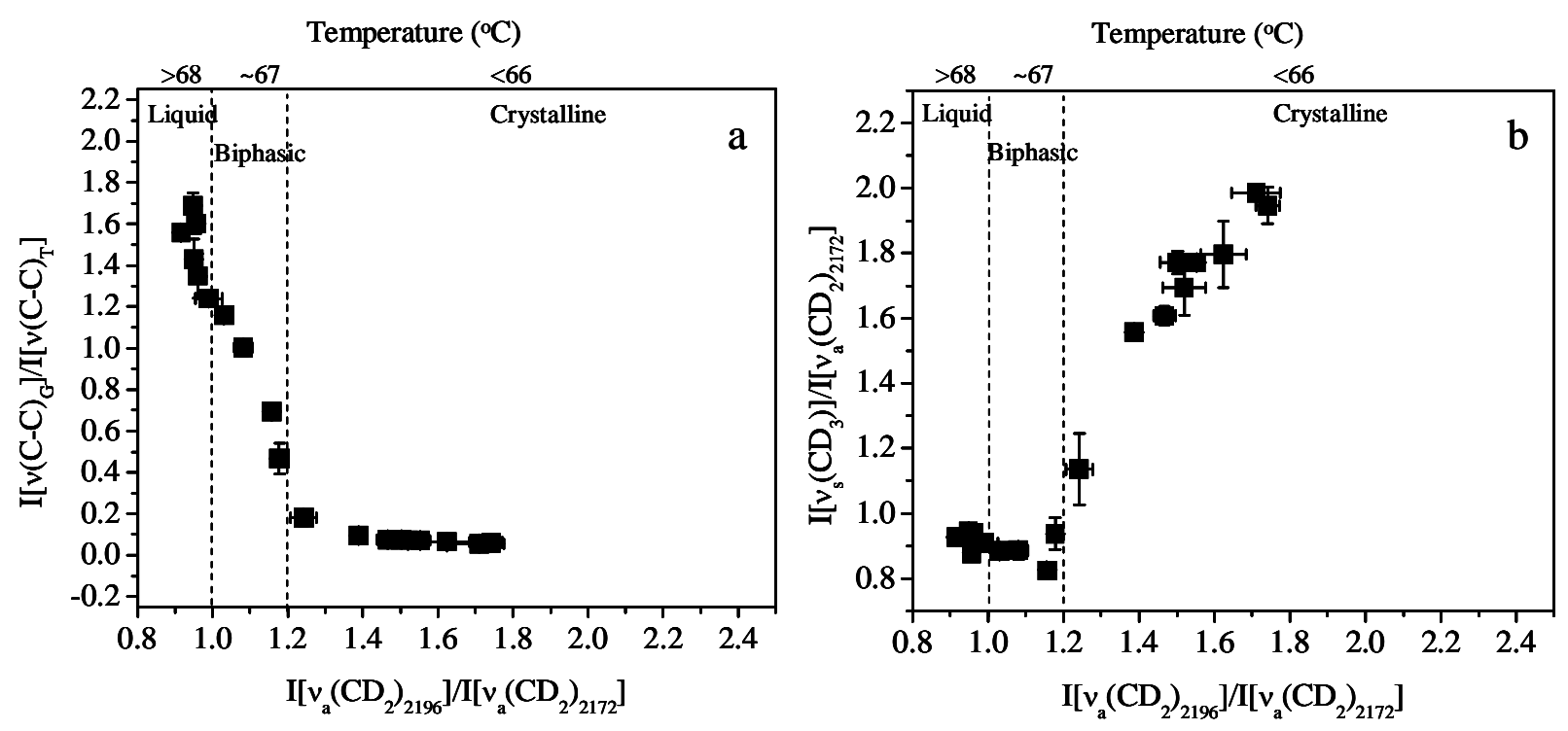

Temperature $\left({ }^{\circ} \mathrm{C}\right)$
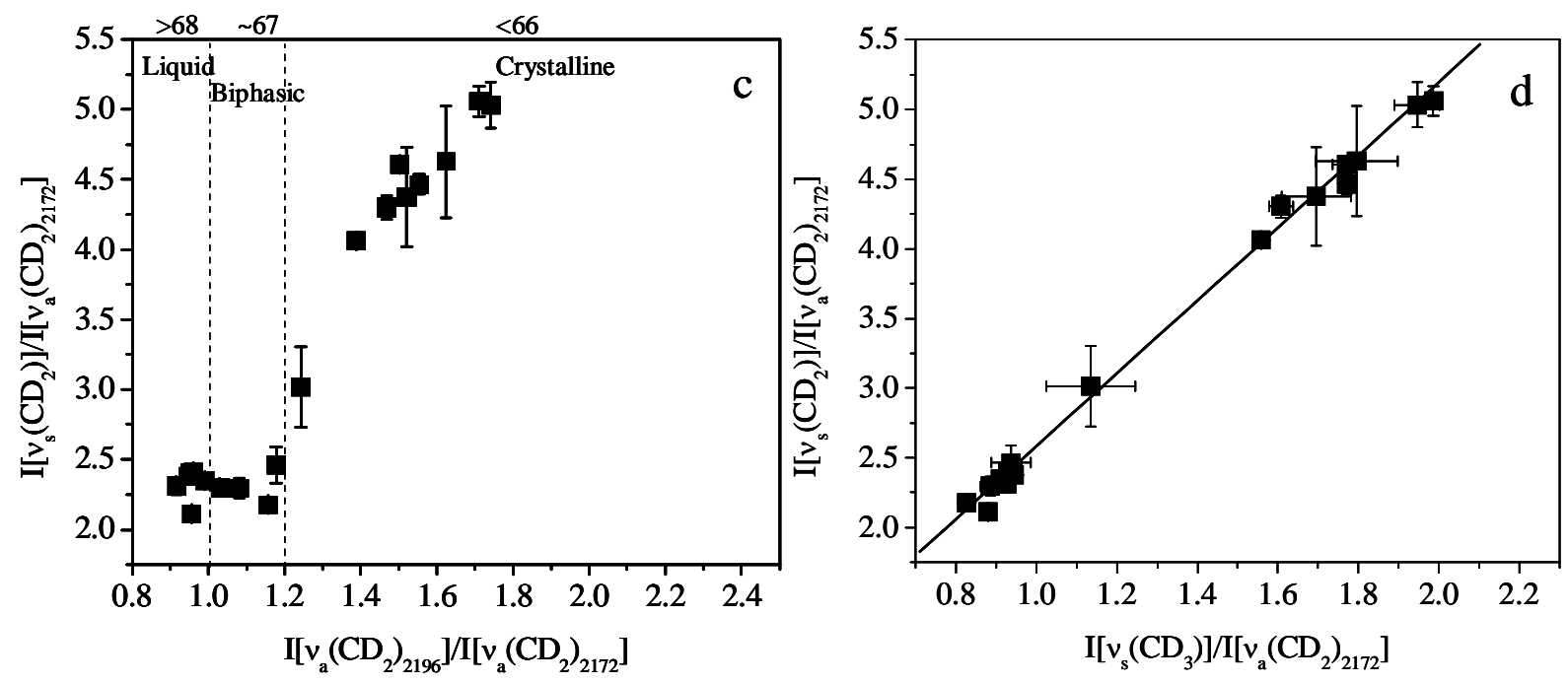

Figure S3: Correlation of a) $\mathrm{I}\left[v(\mathrm{C}-\mathrm{C})_{\mathrm{G}}\right] /\left[v(\mathrm{C}-\mathrm{C})_{\mathrm{T}}\right]$ with $\mathrm{I}\left[\mathrm{v}_{\mathrm{a}}\left(\mathrm{CD}_{2}\right)_{2196}\right] / \mathrm{I}\left[\mathrm{v}_{\mathrm{a}}\left(\mathrm{CD}_{2}\right)_{2172}\right]$, b) $\mathrm{I}\left[\mathrm{v}_{\mathrm{s}}\left(\mathrm{CD}_{3}\right)\right] / \mathrm{I}\left[\mathrm{v}_{\mathrm{a}}\left(\mathrm{CD}_{2}\right)_{2172}\right] \quad$ with $\quad \mathrm{I}\left[\mathrm{v}_{\mathrm{a}}\left(\mathrm{CD}_{2}\right)_{2196}\right] / \mathrm{I}\left[\mathrm{v}_{\mathrm{a}}\left(\mathrm{CD}_{2}\right)_{2172}\right]$, $\mathrm{I}\left[v_{\mathrm{s}}\left(\mathrm{CD}_{2}\right)\right] / \mathrm{I}\left[\mathrm{v}_{\mathrm{a}}\left(\mathrm{CD}_{2}\right)_{2172}\right]$ with $\mathrm{I}\left[v_{\mathrm{a}}\left(\mathrm{CD}_{2}\right)_{2196}\right] / \mathrm{I}\left[\mathrm{v}_{\mathrm{a}}\left(\mathrm{CD}_{2}\right)_{2172}\right]$, and $\left.\mathrm{d}\right)$ $\mathrm{I}\left[v_{\mathrm{s}}\left(\mathrm{CD}_{2}\right)\right] / \mathrm{I}\left[\mathrm{v}_{\mathrm{a}}\left(\mathrm{CD}_{2}\right)_{2172}\right]$ with $\mathrm{I}\left[\mathrm{v}_{\mathrm{s}}\left(\mathrm{CD}_{3}\right)\right] / \mathrm{I}\left[\mathrm{v}_{\mathrm{a}}\left(\mathrm{CD}_{2}\right)_{2172}\right]\left(\mathrm{R}^{2}=0.996\right)$ for stearic acid- $d_{35}$. 

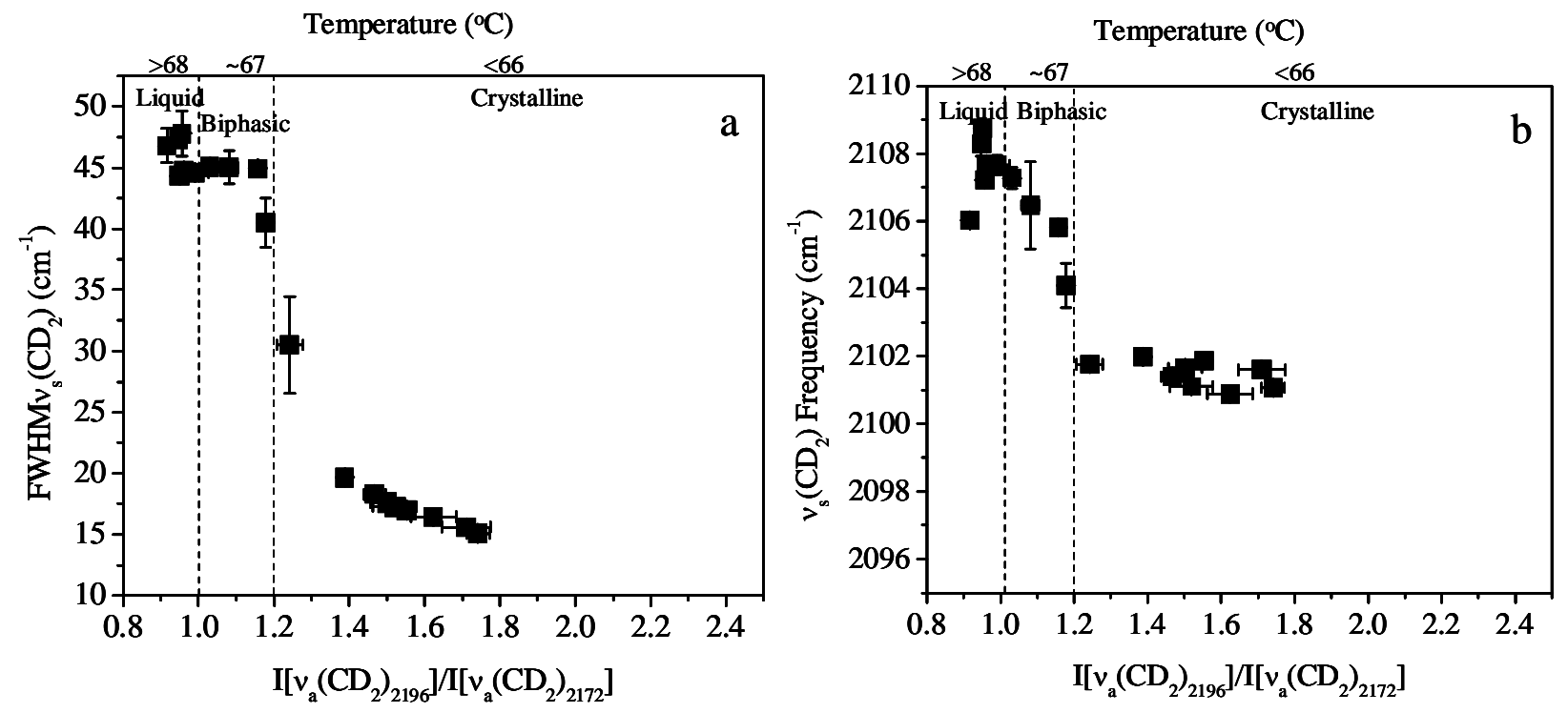

Figure S4: Correlation of a) $v_{\mathrm{s}}\left(\mathrm{CD}_{2}\right)$ full-width-at-half-maximum (FWHM) with $\mathrm{I}\left[v_{\mathrm{a}}\left(\mathrm{CD}_{2}\right)_{2196}\right] /\left[v_{\mathrm{a}}\left(\mathrm{CD}_{2}\right)_{2172}\right]$ and $\left.\mathrm{b}\right) \quad v_{\mathrm{s}}\left(\mathrm{CD}_{2}\right)$ peak frequency with $\mathrm{I}\left[\mathrm{v}_{\mathrm{a}}\left(\mathrm{CD}_{2}\right)_{2196}\right] / \mathrm{I}\left[v_{\mathrm{a}}\left(\mathrm{CD}_{2}\right)_{2172}\right]$ for stearic acid- $d_{35}$. 